\title{
The Dynamics of Vocabulary in Russian Prose (Based on Frequency Dictionaries of the Corpus of Russian Short Stories 1900-1930)
}

\author{
Tatiana G. Skrebtsova \\ Saint Petersburg State University \\ Saint Petersburg, Russia \\ t. skrebtsova@spbu. ru
}

\author{
Alexander O. Grebennikov \\ Saint Petersburg State University \\ Saint Petersburg, Russia \\ a.grebennikov@spbu.ru
}

Tatiana Yu. Sherstinova

National Research University Higher School of Economics

Saint Petersburg, Russia

tsherstinova@hse.ru

\begin{abstract}
The paper presents the results of a study that is part of a large-scale project aimed at studying the changes that took place in the Russian language during the first three decades of the 20th century. In the history of Russia, this period was marked by stormy events that led to a radical change in the state system and the formation of a new society. To quantify the scale of changes that occurred in the language in the result of these dramatic events, it is necessary to analyze the representative volume of linguistic data and to compare different chronological periods in dynamics using quantitative methods. The research was carried out on the data of an annotated sample from the Corpus of the Russian Short Stories of 1900-1930, which contains texts by 300 Russian writers. All the texts in the Corpus are divided into three time frames: 1) the pre-war period (1900-1913), 2) the war and revolutionary years (1914-1922) and 3) the early Soviet period (1923-1930). Frequency distribution of significant vocabulary in dynamics was analyzed, which made it possible to identify the main tendencies in the change of individual words and lexical groups frequencies from one historical period to another and to correlate them with the previously identified dynamics of literary themes. The technique used allows to trace the influence of large-scale political changes on the vocabulary of literary language, to note the peculiarities and tendencies of the writers' worldview in a certain historical period, and also makes it possible to significantly supplement the analysis of the dynamics of literary themes in fiction.
\end{abstract}

Keywords: lexical studies; lexical changes in diachrony; language and style of literary texts; Russian short story; frequency dictionary; corpus linguistics; computational linguistics

DOI: $10.28995 / 2075-7182-2021-20-646-659$

\section{Динамика лексического состава русской художественной прозы (на материале частотных словарей корпуса русских рассказов 1900-1930)}

\author{
Т. Г. Скребцова \\ Санкт-Петербургский \\ государственный университет; \\ Санкт-Петербург, Россия \\ t.skrebtsova@spbu.ru
}

\author{
А. О. Гребенников \\ Санкт-Петербургский \\ государственный университет; \\ Санкт-Петербург, Россия \\ a. grebennikovaspbu .ru
}


Т. Ю. Шерстинова

Научно-исследовательский университет «Высшая школа экономики»

Санкт-Петербург, Россия

tsherstinova@hse.ru

\begin{abstract}
Аннотация
В работе представлены результаты масштабного проекта, направленного на изучение изменений, произошедших в русском языке в течение первых трех десятилетий XX века. В истории нашей страны этот период был отмечен бурными событиями, которые привели к радикальному изменению государственного строя и построению нового общества. Для количественной оценки масштаба изменений, которые произошли в языке в результате драматических событий рассматриваемого периода, необходим анализ представительного объема языкового материала и сравнение разных хронологических срезов в динамическом аспекте с применением количественных методов. Исследование проведено на материале аннотированной выборки из Корпуса русского рассказа 1900-1930 гг., в которой представлены тексты 300 русских писателей. Материалы Корпуса делятся на три временных среза: 1) довоенный период (1900-1913), 2) военно-революционные годы (1914-1922) и 3) советский период (1923-1930). Проанализировано частотное распределение знаменательной лексики в динамике, что позволило выявить яркие тенденции в изменении частотности отдельных слов и лексических групп от одного исторического отрезка к другому и соотнести их с ранее выявленной динамикой тем. Используемая методика позволяет проследить влияние крупномасштабных политических изменений на словарный состав языка художественной литературы, отметить особенности и тенденции мировосприятия авторов в определённый исторический период, а также дает возможность существенно дополнить анализ динамики тем художественных произведений.
\end{abstract}

Ключевые слова: лексика; изменение лексического состава в диахронии; язык и стиль художественных текстов; русский рассказ; частотный словарь; корпусная лингвистика; компьютерная лингвистика

\title{
1 О Корпусе русских рассказов (1900-1930) и его периодизации
}

Настоящее исследование является частью масштабного проекта, направленного на изучение изменений, которые происходили в русском языке в первую треть XX века, - возможно, самый драматический период его развития. Проект включает создание электронного текстового корпуca, содержащего тысячи русских рассказов, написанных в первые три десятилетия прошлого века, и их дальнейший комплексный филологический анализ $[9 ; 10 ; 12]$.

В истории нашей страны этот период был отмечен бурными событиями, приведшими к радикальному изменению государственного строя и построению нового общества. Цепь исторических событий, охватывающих Первую мировую войну, Февральскую и Октябрьскую революцию и Гражданскую войну, обусловила масштабные языковые и стилистические сдвиги. Огромный пласт «отжившей» лексики сменился новыми словами, отражающими новые понятия и идеи, многие слова «из прошлой эпохи» приобрели новые значения или коннотации, произошла трансформация общепринятых речевых структур (в частности, поменялись функциональные частоты многих лексических единиц, сменился набор привычных коллокаций, появились новые модели сочетаемости, фразеологические обороты и т. д.). Помимо «естественного» процесса резких языковых изменений, неизбежно сопровождающих любой переломный период, следует отметить и сознательные действия новой власти, направленные на изменение языковых норм, с тем чтобы еще более размежеваться с уходящей эпохой и подчинить языковую политику государства решению новых актуальных задач.

Для количественной оценки масштаба изменений, которые произошли в языке в результате драматических событий первой трети XX века, необходим анализ представительного объема языкового материала и сравнение разных хронологических срезов в динамическом аспекте с применением количественных методов. Для этой цели создается Корпус русских рассказов первых трех десятилетий XX века, насчитывающий несколько тысяч единиц. Выбор жанра рассказа для изучения языковых и стилистических изменений обусловлен тем, что он принадлежит к числу наиболее распространенных жанров художественной литературы. Это позволяет охватить тексты максимального числа авторов, писавших в исследуемую эпоху, - не только ведущих, но и множества второстепенных, - что способствует репрезентативности коллекции и достоверности выводов. Другая причина выбора именно этого литературного жанра связана со способностью рассказов, в силу своего небольшого объема и предназначенности (как правило) для пуб- 
ликации в периодических изданиях, чутко реагировать на текущие события и улавливать изменения в общественном сознании.

Историческим центром рассматриваемой эпохи, ее переломом, является Октябрьская революция. Все остальные события и процессы рассматриваются или как преддверие центрального события, или как его последствия. Материалы Корпуса делятся на три временных среза: 1) довоенный период: начало XX века до Первой мировой войны (1900-1913), 2) военнореволюционные годы: Первая мировая война, Февральская и Октябрьская революция и Гражданская война (1914-1922) и 3) советский период (1923-1930).

Писатель может быть представлен одним рассказом в каждый временной отрезок, причем в Корпус не включаются рассказы, написанные в эмиграции. Так, покинувший Россию в 1920 г. И. А. Бунин представлен одним рассказом за довоенный период и еще одним - за военнореволюционный период.

Аннотированная выборка из Корпуса, в которой представлены тексты 300 русских писателей (приблизительно по 100 за каждый период ${ }^{1}$, более 1 млн. словоупотреблений) служит своеобразным полигоном для разностороннего изучения материала. Наряду с творчеством признанных мастеров пера - Чеховым, Буниным, Горьким, Куприным, Вересаевым, Булгаковым, Шмелевым, Грином, Тэффи, Замятиным, Зощенко, Катаевым, Пильняком, Кавериным, Гайдаром, Олешей, Бабелем, Платоновым, Пришвиным и др. - она включает произведения авторов, известных лишь узким специалистам. На основе этой выборки проводятся исследования, затрагивающие не только языковые изменения, но и динамику тем, а также композиционную специфику русских рассказов $[7 ; 8 ; 12-17]$.

Настоящее исследование также базируется на данном подкорпусе. Оно посвящено анализу наиболее частотных знаменательных лексем, собранных как отдельно по каждому из трех периодов, так и совокупно по всему историческому отрезку длиной в три десятилетия. Следует подчеркнуть, что выделенные периоды принципиально отличны друг от друга: можно сказать, что второй (военный) противопоставлен первому и третьему (мирным), однако первый и третий кардинально различаются между собой по общественно-политическому устройству. Поэтому их попарное сравнение представляет несомненный интерес, в особенности на фоне выявленной ранее динамики тем $[14 ; 15 ; 17]$.

В предыдущих исследованиях, выполненных на материале Корпуса русского рассказа, уже было отмечено, что масштабное сопоставление данных, позволяющее выявить лексическое своеобразие эпохи, обусловленное общественно-политической атмосферой и отражающее тенденции в языковом употреблении, возможно только путем сравнения верхних рангов знаменательной лексики с соответствующими рангами писательских словарей и словаря языка в целом, во-первых, и, что гораздо более желательно, с аналогичным электронным корпусом отечественных литературных произведений, относящихся к какому-либо другому историческому периоду, во-вторых.

В частности, в [11] были наглядно представлены результаты такого сопоставления для первого (довоенного) периода рассказов из нашей выборки. Одновременно установлено, что сравнение со словарями отдельных авторов обнаруживает значительную индивидуально-авторскую вариативность выделенных лексем, затрудняющую выделение общих тенденций [1-5]. Сравнение же со словарем языка в целом неизбежно сталкивается с проблемой представленности в нем множества жанров, и, хотя результаты зачастую интересны и показательны, они искажены значительной долей статистического «шума» [6; 7]. Поэтому в данном исследовании было принято решение от него отказаться.

Напротив, было установлено, что сопоставление рассказов 1900-1913 гг. с русскими рассказами начала XXI века, полученными на основе Национального корпуса русского языка (НКРЯ), обладает значительным стилеразличительным потенциалом [6]. Оно дает возможность подтвердить или опровергнуть справедливость сделанных предположений о том, что именно принадлежность к разным историческим периодам прежде всего обусловливает наблюдаемые различия в частотном распределении лексем.

\footnotetext{
${ }^{1}$ Было выбрано 300 авторов, но из-за того, что некоторые из них представлены более, чем в одном периоде, выборка составляет не 300 , а 310 рассказов.
} 


\section{2 Методология исследования}

На материале аннотированной выборки из Корпуса русских рассказов были построены расположенные в порядке убывания частот частотные словари как для выборки в целом, так и для каждого из исторических периодов объемом 24316 лексем, 376513 словоформ для первого периода; 24617 лексем, 303588 словоформ для второго периода; 30560 лексем; 383430 словоформ для третьего периода и 124081 лексема, 1077970 словоформ для выборки в целом.

В качестве объекта исследования были выбраны знаменательные слова, расположенные в верхних зонах частотного распределения (с частотой выше 100). Для каждого периода их количество превысило 200, и составило около 800 для выборки в целом.

При сравнении частотного распределения лексики в разные периоды (см. раздел 3) используется такой параметр, как ранг лексемы (иначе говоря, ее статистический вес). Вследствие некоторой разницы в объемах полученных словарей учет именно рангов, а не абсолютных частот является корректным решением.

В тексте статьи для описания динамики частотности отдельных слов используется следующая нотация. В скобках при слове указывается его текущий ранг; если в предшествующий период оно также входило в рассматриваемую верхнюю зону рангового распределения, указывается и его прежний ранг, и два числа соединяются стрелкой. Например, при сравнении второго периода с первым запись солдат $(116 \rightarrow 62)$ означает, что данное слово имело 116-й ранг в первый период и переместилось на 62-ю позицию во второй период. Если слово в предшествующий период находилось вне верхней зоны, а в рассматриваемый период в нее вошло, первое число отсутствует, ср. офищер $(\rightarrow 169)$. Если же, напротив, в более ранний период слово присутствовало в верхней зоне, а в рассматриваемый период ее покинуло, отсутствует второе число, cp. красивый $(143 \rightarrow)$. При сопоставлении данных за три периода возможна ситуация, когда некоторое слово присутствует в верхней зоне в первый и третий периоды, но отсутствует во второй - в таком случае запись выглядит следующим образом: смех $(257 \rightarrow \rightarrow 234)$.

Несколько слов следует сказать о специфике работы автоматической программы лемматизации ${ }^{2}$. В частности, парные глаголы совершенного и несовершенного вида рассматриваются в качестве отдельных лексем (что представляется методологически правильным в силу частых расхождений в наборе их значений). То же относится к супплетивным формам (так, ниже отдельно фигурируют формы ребенок и дети). Имена собственные по понятным причинам были исключены из частотных списков. Некоторые из них из-за графического совпадения с именами нарицательными могут влиять на статистику последних, ср. Вера - вера. В подобных случаях соответствующие общие имена также не принимались во внимание.

Заметим, что при автоматической обработке неизбежны некоторые погрешности, связанные с неправильным определением леммы (большой и больший, стоять и стоить, пол и пола, лес и леса и пр.), омонимией (мир, язык) и грамматической неоднозначностью (стать). Во избежание ошибочных заключений подобные случаи также исключены из рассмотрения.

При интерпретации полученных данных полисемичные слова рассматриваются в совокупности всех своих лексико-семантических вариантов, что, разумеется, ведет к некоторым погрешностям, но является неизбежным следствием применения автоматических методов. Представляется, что эта погрешность невелика при рассмотрении небольших и компактно расположенных исторических отрезков.

\section{3 Динамика частотных лексем по периодам}

Примечательно, что шесть самых верхних рангов во всех периодах занимают одни и те же слова (различаясь лишь позициями): говорить, сказать, один, глаз, рука, мочь. Остальной материал демонстрирует как сходства, так и существенные различия. Посредством сравнения более позднего периода с более ранним(и) мы стремимся выделить: 1) новые слова, вошедшие в верхнюю зону частотного распределения; 2) слова, которые ушли из нее и 3) слова, демонстрирую-

\footnotetext{
2 Словари строились при помощи программы "UNILEX" (разработка Институт русского языка им. Виноградова). См. Аношкина Ж.Г. Тексто-ориентированная компонента АЛС УНИЛЕКС (УНИЛЕКС-Т) // Альманах «Говор», № 5, 1995, стр. 7-29.
} 
щие выраженную динамику частоты. Мы анализируем эти явления, пытаясь связать их с общественно-политической обстановкой соответствующего времени и выявленной ранее динамикой тем [7-9].

\section{Сравнение второго (военно-революционного) периода с первым (довоенным)}

На фоне довоенных рассказов в произведениях второго периода закономерно увеличивается доля военной тематики $[17$, с. 50$]$ и становится актуальной национальная самоидентификация, что соответственно проявляется во вхождении в верхнюю зону частотного распределения слов офицер $(\rightarrow 169)$ и русский $(\rightarrow 182)$. Военным временем, по-видимому, объясняется и вхождение слов дьякон $(\rightarrow 83)$ и писать $(\rightarrow 181)$ - в связи с возросшей ролью церкви, вынужденным разделением семей, тревогой за близких и потребностью в переписке. Указанные корреляции подкрепляются динамикой роста у слов бог $(89 \rightarrow 65)$, солдат $(116 \rightarrow 62)$ и письмо $(190 \rightarrow 117)$, которые были в верхней зоне и в первый период, но переместились на более высокие позиции рангового распределения.

Еще одним индикатором смены эпохи можно считать уход слова можно $(80 \rightarrow)$, с одной стороны, и появление в верхней зоне слов должный $(\rightarrow 76)$ и нельзя $(\rightarrow 147)$ - с другой, что сигнализирует о наступлении более сурового и жесткого времени, связанного с ограничениями, запретами и принуждениями (глагол мочь, впрочем, сохраняет свой шестой ранг). В целом, можно сказать, что модальность долженствования вытесняет модальность возможности. В такой период важной оказывается концентрация на текущем моменте - отсюда вхождение слов сегодня $(\rightarrow 172)$, сейчас $(\rightarrow 71)$, теперь $(\rightarrow 20)$, наконеи $(\rightarrow 186)$.

Вполне закономерным выглядит уход из верхней зоны подавляющего большинства слов, обозначающих положительные эмоции, а именно: праздник $(268 \rightarrow)$, добрый $(265 \rightarrow)$, светлый $(236$ $\rightarrow)$, красивый $(143 \rightarrow)$, веселый $(152 \rightarrow)$, весело $(182 \rightarrow)$, смех $(257 \rightarrow)$, счастье $(228 \rightarrow)$, чувство $(126 \rightarrow)$, ульбка $(219 \rightarrow)$, улыбаться $(173 \rightarrow)$, тихий $(128 \rightarrow)$, тишина $(249 \rightarrow)$. (Некоторые из них, а именно весельй, смех, тихий и тишина, возвращаются в третий период.) Этот факт коррелирует с уменьшением значимости широкого круга тем, связанных с любовью, семьей, помощью ближнему, благотворительностью $[7$, с. 54,56$]$. В связи с этим обращает на себя внимание уход слов ребенок $(213 \rightarrow)$, играть $(227 \rightarrow)$ и снижение частоты слова дети $(69 \rightarrow 107)$, которое все-таки удерживается в верхней зоне.

Из прочих слов, покинувших верхнюю зону, отметим пить $(267 \rightarrow)$ и пьяный $(241 \rightarrow)$ - этот факт можно объяснить введением сухого закона и соответственным снижением темы пьянства, которая, очевидно, повышает частоту данных слов [7, с. 53]. Уход слов барин $(258 \rightarrow)$, хозяин $(226 \rightarrow)$, работать $(218 \rightarrow)$, рабочий $(202 \rightarrow)$ связан, по-видимому, с актуализацией темы войны, вытесняющей мирный труд. По аналогичной причине из верхних рангов пропало слово сmyдент $(217 \rightarrow)$.

Заметим, что большинство «пропавших» слов так и не вернулось в верхние ранги частоты в третий, советский, период.

Справедливости ради следует упомянуть и то, что можно назвать контрпримерами, а именно слова, сохранение или исчезновение которых не получается объяснить выявленной ранее динамикой тем. К примеру, в верхней зоне частотного распределения осталось слово смеяться, хотя ранг его и понизился $(131 \rightarrow 183)$. Напротив, ушли слова страшный $(135 \rightarrow)$, страх $(253 \rightarrow)$, ужас $(166 \rightarrow)$, дрожать $(185 \rightarrow)$, умереть $(191 \rightarrow)$, тоска $(207 \rightarrow)$, больной $(210 \rightarrow)$, которые, казалось бы, гораздо более востребованы в эпоху войн и революций, чем в мирное время. Несмотря на заметный и вполне объяснимый рост «мистических» тем, связанных с видениями, предчувствиями, снами, мечтами [7, с. 56], верхнюю зону покинули слова показаться $(194 \rightarrow)$, похожий $(174 \rightarrow)$, странный $(155 \rightarrow)$.

\section{Сравнение третьего (советского) периода с предшествующими}

Характерной особенностью третьего периода является вхождение в верхнюю зону частотного распределения большого числа конкретных существительных, связанных с сельской жизнью: дед $(\rightarrow 114)$, старуха $(\rightarrow 166)$, ребята $(\rightarrow 183)$, хлеб $(\rightarrow 152)$, поле $(\rightarrow 238)$, куст $(\rightarrow 255)$, трава 
$(\rightarrow 245)$, собака $(\rightarrow 165)$, конь $(\rightarrow 204)$, птица $(\rightarrow 230)$ - и техническим прогрессом: машина $(\rightarrow 250)$, поезд ( $\rightarrow 256)$, вагон $(\rightarrow 173)$, ход $(\rightarrow 177)$. Это коррелирует с выраженным ростом соответствующих тем [17, с. 51-52]. Число абстрактных существительных, напротив, сокращается.

Список частей тела человека, и так широко представленных в верхней зоне частотного распределения, в советский период увеличивается чуть ли не вдвое. Так, к уже имеющимся единицам рука, глаз, голова, лищо, губа, зуб, нога, тело, плечо, палещ, волос добавились слова нос $(\rightarrow 121)$, ухо $(\rightarrow 184)$, лоб $(\rightarrow 216)$, шея $(\rightarrow 275)$, щека $(\rightarrow 264)$, борода $(\rightarrow 268)$, бок $(\rightarrow 252)$, колено $(\rightarrow 205)$.

Расширился также набор числительных - к один, два, три, первый добавились лексемы четыре $(\rightarrow 262)$, пять $(\rightarrow 218)$, второй $(\rightarrow 258)$. На фоне общего уменьшения числа прилагательных возвращается слово синий и появляются такие цветообозначения, как желтый $(\rightarrow 221)$ и зеленый $(\rightarrow 222)$. (Белый и черный стабильно занимают высокие позиции, а по поводу красный см. ниже).

Появилось слово вперед ( $\rightarrow 170)$, что, по-видимому, объясняется актуализированными темами технического прогресса и светлого будущего [17, с. 51]. Политика ликвидации безграмотности и культпросвета обусловила вхождение в верхнюю зону слова книга $(\rightarrow 208)$.

Вновь появилось пропавшее во второй период слово можно $(80 \rightarrow \rightarrow 95)$. Нельзя $(\rightarrow 147 \rightarrow)$ ушло, но должный $(\rightarrow 76 \rightarrow 67)$ сохранилось. Слово хотеться $(101 \rightarrow 150 \rightarrow 227)$ демонстрирует последовательное снижение ранга, при том что хотеть $(19 \rightarrow 23 \rightarrow 23)$ на протяжении всех трех периодов занимает примерно одинаковое высокое положение в частотном распределении.

Показателем наступившего мирного времени можно считать возвращение в верхнюю зону частотного распределения слов работать $(218 \rightarrow \rightarrow 109)$, рабочий $(202 \rightarrow \rightarrow 112)$, весельй $(152 \rightarrow$ $\rightarrow 232)$, смех $(257 \rightarrow \rightarrow 234)$, тихий $(128 \rightarrow \rightarrow 196)$, тишина $(249 \rightarrow \rightarrow 231)$, играть $(227 \rightarrow \rightarrow 207)$, разговор $(186 \rightarrow \rightarrow 209)$.

Обращает на себя внимание вхождение в верхнюю зону слов ружье $(\rightarrow 278)$, poта $(\rightarrow 218)$ и кровь $(\rightarrow 105)$. На первый взгляд, более естественным казалось бы их появление в предыдущий, военно-революционный, период. Возможное объяснение заключается в том, что в нашей выборке за третий период рассказов про Гражданскую войну оказалось примерно в два раза больше, чем за второй, т. е. тогда, когда эта война шла. Это «отставание» литературы от жизни обусловлено рядом факторов. Из наиболее очевидных упомянем тот банальный факт, что на написание рассказа требуется время, затем проходит еще какое-то время до его публикации, которая сама по себе затруднена в условиях затянувшейся войны, политических волнений и экономической разрухи. К тому же, для осознания столь масштабных событий, приведших к радикальному изменению общественной жизни, необходима дистанция («большое видится на расстоянии»). Отсюда своеобразный отсроченный эффект: чем крупнее историческое событие, тем дольше оно сохраняет свою значимость, в том числе в литературе и искусстве.

Вполне закономерно верхнюю зону частотного распределения покинули слова офицер $(\rightarrow 169 \rightarrow)$ (в Красной Армии воинские звания были упразднены), солдат $(116 \rightarrow 62 \rightarrow)$ и дьякон $(\rightarrow 83 \rightarrow)$. Слово бог $(89 \rightarrow 65 \rightarrow 211)$ осталось, но его ранг заметно снизился, что обусловлено антирелигиозной политикой советской власти.

Примечателен уход из верхней зоны слов гость $(165 \rightarrow)$ и знакомый $(193 \rightarrow)$, присутствовавших там и в первый, и во второй периоды. Социальные отношения теперь сводятся в основном к семейным и трудовым, причем семейные связи угасают: у слов муж $(146 \rightarrow 166 \rightarrow 236)$, жена $(52 \rightarrow 84 \rightarrow 139)$, дети $(69 \rightarrow 107 \rightarrow 198)$ наблюдается снижение ранга, а слово ребенок так и не вернулось в верхнюю зону.

В числе прочих слов, присутствовавших в верхней зоне в оба предшествующих периода, но ушедших в советское время, отметим господин $(145 \rightarrow 146 \rightarrow$ ) (дореволюционная тематика практически сошла на нет), толпа $(79 \rightarrow 103 \rightarrow)$, мильй $(122 \rightarrow 176 \rightarrow)$, любовь $(134 \rightarrow 112 \rightarrow)$, письмо $(190 \rightarrow 117 \rightarrow)$. 


\section{Общая динамика частот на протяжении трех периодов}

В этом разделе мы сосредоточимся на словах, присутствующих в верхней зоне частотного распределения на протяжении всех трех периодов. Прежде всего нас интересуют случаи ярко выраженного последовательного изменения ранга. Они разделяются на 1) случаи поступательного роста ранга и 2) случаи поступательного снижения ранга. Эти примеры, как мы предполагаем, обусловлены внешним контекстом - коренным переворотом политического строя, сломом прежних социальных отношений и построением нового общества.

Возможно, наиболее ярким примером первого типа может служить заметная активизация слова товарищ $(198 \rightarrow 105 \rightarrow 38)$ как индикатора новой советской власти. Здесь же уместно упомянуть схожую динамику слова красный $(163 \rightarrow 110 \rightarrow 54)$. Помимо этого, наблюдается существенное повышение ранга у слов, которые можно прямо или опосредованно связать с жизнью на селе, ср. деревня $(250 \rightarrow 192 \rightarrow 150)$, народ $(224 \rightarrow 198 \rightarrow 164)$, мужик $(252 \rightarrow 144 \rightarrow 61)$, баба $(\rightarrow 143 \rightarrow 81)$, сын $\quad(183 \rightarrow 161 \rightarrow 126)$, брат $\quad(255 \rightarrow 136 \rightarrow 120)$, утро $\quad(100 \rightarrow 81 \rightarrow 55)$, лошадь $(176 \rightarrow 139 \rightarrow 93)$, бежать $(169 \rightarrow 134 \rightarrow 85)$, дорога $(209 \rightarrow 168 \rightarrow 134)$, ветер $(216 \rightarrow 149 \rightarrow 113)$.

Примеры второго типа включают слова, обозначающие внутреннюю жизнь человека, ср. любить $(39 \rightarrow 43 \rightarrow 69)$, чувствовать $(54 \rightarrow 152 \rightarrow 197)$, смеяться $(131 \rightarrow 183 \rightarrow 189)$, душа $(42 \rightarrow 35 \rightarrow$ $151)$, мысль $(62 \rightarrow 102 \rightarrow 130)$, а также его связи с близкими, ср. жена $(52 \rightarrow 84 \rightarrow 139)$, муж $(146 \rightarrow 166 \rightarrow 236)$, дети $(69 \rightarrow 107 \rightarrow 198)$. Эта же динамика характерна для слов молодой $(58 \rightarrow 59 \rightarrow 147)$, казаться $(14 \rightarrow 51 \rightarrow 58)$ и смерть $(106 \rightarrow 163 \rightarrow 223)$.

Последовательное уменьшение ранга зафиксировано у слова деньги $(133 \rightarrow 178 \rightarrow 249)$, что обусловлено снижением покупательной способности денег в военно-революционный период, эмиссией разнообразных бумажных знаков, имевших сомнительную ценность, а затем денежными реформами советской власти (деноминациями). Заметим, что соответственно снижается частота темы, связанной с оппозицией богатства и бедности: после Гражданской войны в Советской России просто не осталось богатых людей [17, с. 53].

Кроме случаев поступательного изменения ранга (будь то рост или падение) имеются слова, у которых динамика употребления может быть представлена в виде ломаной линии. Иными словами, они имеют точку перелома во втором периоде, а показатели первого и третьего периодов достаточно схожи. Однако их перечень, как нам кажется, не дает основания для каких-либо обобщений и корреляций с исторической ситуацией. В связи с этим мы опускаем данные о динамике рангов, ограничиваясь простым перечислением. Так, возрастание ранга во второй период фиксируется у слов живой, читать, легкий, просить, высокий, поднять, бояться, ждать, дать. Напротив, падение ранга во второй период наблюдается у слов девушка, длинный, тяжельй, угол, воздух, подумать, свет.

Достаточно большое число слов вообще не имеют значительных колебаний ранга, образуя своеобразные «инварианты». Они расположены преимущественно в пределах верхних 80 рангов - ниже разброс, как правило, довольно велик. (Хотя и в этих рамках иногда случаются резкие колебания: достаточно указать на слова красньй и товарищ, см. выше.)

К словам, стабильно характеризующимся высокой частотой, относятся основные глаголы движения (идти, ходить, выйти, пойти, уйти), позы (сидеть, стоять, лежать), речи (говорить, сказать, спросить, молчать), чувственного восприятия (видеть, смотреть), а также глаголы жить, взять, спать, хотеть, любить, казаться. Из высокочастотных прилагательных упомянем последний, большой, маленький, старый, новый, белый, черный и примыкающие к ним местоимения другой и каждый. Существительные верхних рангов включают такие группы слов, как город - улииа - дом, комната - стол, человек - люди, время - год - час, названия частей тела (голова, лицо, глаз, нога, рука), времен суток (день, ночь, утро, вечер), а также лексемы жизнь, место, сторона, земля, дело, отеи, сердие.

\section{4 Заключение}

В настоящей статье проанализировано частотное распределение знаменательной лексики на материале выборки из Корпуса русских рассказов (1900-1930). Внимательное рассмотрение верхней зоны частотного распределения позволило выявить яркие тенденции в изменении ча- 
стотности отдельных слов и лексических групп от одного исторического отрезка к другому и соотнести их с ранее выявленной динамикой тем.

Среди возможных направлений дальнейшего анализа наиболее интересным и перспективным представляется сопоставление полученных данных с частотностью лексических единиц в русских рассказах начала XXI века. Оно позволяет в более широком ракурсе оценить языковые и стилистические изменения в языке литературных произведений и задуматься об их причинах. Мы рассматриваем это в качестве самостоятельного направления дальнейших исследований.

В целом, анализ наших данных показывает, что частотные распределения, построенные на материале представительных выборок из масштабного корпуса текстов, могут служить хорошим индикатором динамики лексического состава художественной прозы произведений отдельной эпохи. Используемая методика позволяет проследить влияние крупномасштабных политических изменений на словарный став языка художественной литературы, отметить особенности и тенденции мировосприятия авторов в определённый исторический период, а также позволяет существенно дополнить анализ динамики тем произведений.

\section{Acknowledgements}

Работа выполнена при поддержке Российского фонда фундаментальных исследований, грант № 17-29-09173 «Русский язык на рубеже радикальных исторических перемен: исследование языка и стиля предреволюционной, революционной и постреволюционной художественной прозы методами математической и компьютерной лингвистики (на материале русского расска3a)».

\section{References}

[1] Grebennikov A.O. (2019), Measures of lexical similarity of frequency dictionaries [Mery leksicheskogo skhodstva chastotnykh slovarey], Structural and Applied Linguistics [Strukturnaya i Prikladnaya Lingvistika], No. 12, Saint Petersburg, pp. 61-68.

[2] Grebennikov A.O., Martynenko G.Ya. (Ed.) (1999), Frequency Dictionary of the Short Stories by Anton P. Chekhov [Chastotnyy slovar rasskazov A.P. Chekhova], Izdatelstvo Sankt-Peterburgskogo Universiteta, Saint Petersburg.

[3] Grebennikov A.O., Martynenko G.Ya. (Ed.) (2003), Frequency Dictionary of the Short Stories by Leonid N. Andreev [Chastotnyy slovar rasskazov L.N. Andreeva], Izdatelstvo Sankt-Peterburgskogo Universiteta, Saint Petersburg.

[4] Grebennikov A.O., Martynenko G.Ya. (Ed.) (2006), Frequency Dictionary of the Short Stories by Alexander I. Kuprin [Chastotnyy slovar rasskazov A.I. Kuprina], Izdatelstvo Sankt-Peterburgskogo universiteta, Saint Petersburg.

[5] Grebennikov A.O., Martynenko G.Ya. (Ed.) (2011), Frequency Dictionary of the Short Stories by Ivan A. Bunin [Chastotnyy slovar rasskazov A.I. Bunina]. Izdatelstvo Sankt-Peterburgskogo universiteta, Saint Petersburg.

[6] Grebennikov A.O., Marusenko N.M. (2020), Corpus of the Russian story of the early XX century. An example of linguistic statistical analysis [Korpus russkogo rasskaza nachala XX veka. Primer lingvostatisticheskogo analiza], Computational Linguistics and Computational Ontologies: Proceedings of the XXIII Joint Conference "Internet and Modern Society" (IMS-2020) [Komp'yuternaya Lingvistika i Vychislitel'nye Ontologii. Trudy XXIII Mezhdunarodnoj Ob"edinennoj Konferencii «Internet i Sovremennoe Obshchestvo» (IMS-2020)], Saint Petersburg, pp. 21-29.

[7] Grebennikov A.O., Skrebtsova T.G. (2019), Yazykovaya kartina mira v russkom rasskaze nachala XX veka [Linguistic picture of the world in the Russian story of the early XX century], Philosophy and Humanities in the Information Society [Filosofija i gumanitarnyie nauki v informatsionnom obschestve], No. 3, pp. 8292.

[8] Martynenko G., Sherstinova T. (2018), Emotional Waves of a Plot in Literary Texts: New Approaches for Investigation of the Dynamics in Digital Culture, Digital Transformation and Global Society. Communications in Computer and Information Science, Vol. 859, Saint Petersburg, pp. 299-309.

[9] Martynenko G.Ya., Sherstinova T.Yu, Popova T.I., Melnik A.G. (2018), Methodological Issues Related with the Compilationof DigitalAnthology of Russian Short Stories (the First Third of the 20th Century) [Metodologicheskie problemy sozdaniya Komp'yuternoj Antologii Russkogo Rasskaza kak Yazykovogo Resursa Dlya Issledovaniya Yazyka i Stilya Russkoj Khudozhestvennoj Prozy v Ehpokhu Revolyucionnykh Peremen (Pervoj Treti XX veka)], Computational Linguistics and Computational Ontologies: Proceedings of the 
XXI Joint Conference "Internet and Modern Society" (IMS-2018) [Komp'yuternaya Lingvistika i Vychislitel'nye Ontologii. Trudy XXI Mezhdunarodnoj Ob"edinennoj Konferencii «Internet i Sovremennoe Obshchestvo» (IMS-2018)], Saint Petersburg, pp. 99-104. Access mode: https://openbooks.itmo.ru/ru/file/8421/8421.pdf

[10] Martynenko G.Ya., Sherstinova T.Yu., Popova T.I., Melnik A.G., Zamirajlova E.V. (2018), On the principles of creation of the Russian short stories corpus of the first third of the 20th century [O printsipakh sozdaniya korpusa russkogo rasskaza pervoy treti XX veka], Proceedings of the XV International Conference on Computer and Cognitive Linguistics “TEL 2018”, Kazan, pp. 180-197.

[11] Sherstinova T., Grebennikov A., Skrebtsova T., Guseva A., Gukasian M., Egoshina I., Turygina M. (2020), Frequency word lists and their variability (the case of Russian fiction in 1900-1930), Proceedings of the 27th Conference of FRUCT Association, Helsinki, № 27, pp. 366-373.

[12] Sherstinova T., Martynenko G. (2020) Linguistic and stylistic parameters for the study of literary language in the Corpus of Russian short stories of the first third of the 20th century. R. Piotrowski's Readings in Language Engineering and Applied Linguistics, Proc. of the III International Conference on Language Engineering and Applied Linguistics (PRLEAL-2019), Saint Petersburg, Russia. CEUR Workshop Proceedings, Vol. 2552, pp. 105-120. Access mode: http://ceur-ws.org/Vol-2552/.

[13] Sherstinova T., Mitrofanova O., Skrebtsova T., Zamiraylova E., Kirina M. (2020), Topic modelling with NMF vs. expert topic annotation: the case study of Russian fiction, Advances in Computational Intelligence. MICAI 2020. Lecture Notes in Computer Science, vol. 12469, Springer, Cham, pp. 134-151. Access mode: https://doi.org/10.1007/978-3-030-60887-3_13.

[14] Sherstinova T., Skrebtsova T. (2020), Russian literature around the October revolution: A quantitative exploratory study of literary themes and narrative structure in Russian short stories of 1900-1930, Proceedings of the International Conference "Internet and Modern Society" (IMS-2020), St. Petersburg, pp. 117128. Access mode: http://ceur-ws.org/Vol-2813/rpaper09.pdf

[15] Skrebtsova T. (2020) Thematic tagging of literary fiction: the case of early 20th century Russian short stories, Proceedings of the International Conference "Internet and Modern Society" (IMS-2020), St. Petersburg, pp. 265-276. Access mode: http://ceur-ws.org/Vol-2813/rpaper20.pdf

[16] Skrebtsova T.G. (2019), The structure of the narrative in the Russian story of the early XX century [Struktura narrativa v russkom rasskaze nachala XX veka], Proceedings of the International Conference “Corpus linguistics-2019” [Trudy Mezhdunarodnoy Konferentsii “Korpusnaya Lingvistika-2019”], St. Petersburg, pp. 426-431.

[17] Skrebtsova T.G. (2020), Dynamics of themes of Russian stories of the early XX century [Dinamika tem russkikh rasskazov nachala XX veka], Philosophy and Humanities in the Information Society [Filosofija $\mathrm{i}$ gumanitarnyie nauki v informatsionnom obschestve], No. 3, pp. 45-60. 
Приложение. Ранги знаменательной лексики по частоте употребления в каждом из трех исторических периодов, верхняя зона частот (250 слов).

\begin{tabular}{|c|c|c|c|}
\hline \multirow[t]{2}{*}{ СЛОВО } & $\begin{array}{c}\text { 1-й ПЕРИОД } \\
\text { (1900-1913) }\end{array}$ & $\begin{array}{c}\text { 2-й ПЕРИОД } \\
\text { (1914-1922) }\end{array}$ & $\begin{array}{c}\text { 3-й ПЕРИОД } \\
(1923-1930)\end{array}$ \\
\hline & РАНГ & РАНГ & РАHГ \\
\hline сказать & 1 & 2 & 3 \\
\hline один & 2 & 3 & 4 \\
\hline глаз & 3 & 4 & 2 \\
\hline говорить & 4 & 1 & 5 \\
\hline рука & 5 & 5 & 1 \\
\hline мочь & 6 & 6 & 6 \\
\hline лицо & 7 & 9 & 12 \\
\hline знать & 8 & 7 & 8 \\
\hline другой & 9 & 12 & 13 \\
\hline голова & 10 & 10 & 7 \\
\hline идти & 11 & 8 & 9 \\
\hline жизнь & 12 & 19 & 33 \\
\hline человек & 13 & 14 & 11 \\
\hline казаться & 14 & 51 & 58 \\
\hline думать & 15 & 22 & 20 \\
\hline люди & 16 & 15 & 29 \\
\hline время & 17 & 37 & 24 \\
\hline голос & 18 & 26 & 30 \\
\hline хотеть & 19 & 23 & 23 \\
\hline видеть & 20 & 30 & 22 \\
\hline дом & 21 & 32 & 37 \\
\hline большой & 22 & 16 & 17 \\
\hline смотреть & 23 & 38 & 31 \\
\hline два & 24 & 17 & 14 \\
\hline ночь & 25 & 21 & 26 \\
\hline pa3 & 26 & 34 & 28 \\
\hline дело & 27 & 27 & 18 \\
\hline сидеть & 28 & 29 & 21 \\
\hline слово & 29 & 28 & 40 \\
\hline пойти & 30 & 31 & 19 \\
\hline нога & 31 & 25 & 15 \\
\hline земля & 32 & 40 & 27 \\
\hline друг & 33 & 42 & 88 \\
\hline комната & 34 & 56 & 56 \\
\hline окно & 35 & 45 & 42 \\
\hline дверь & 36 & 33 & 25 \\
\hline есть & 37 & 36 & 46 \\
\hline белый & 38 & 39 & 32 \\
\hline любить & 39 & 43 & 69 \\
\hline стоять & 40 & 50 & 44 \\
\hline черный & 41 & 46 & 36 \\
\hline душа & 42 & 35 & 151 \\
\hline первый & 43 & 60 & 43 \\
\hline темный & 44 & 118 & 101 \\
\hline спать & 45 & 58 & 53 \\
\hline спросить & 46 & 49 & 57 \\
\hline сердце & 47 & 54 & 77 \\
\hline час & 48 & 70 & 71 \\
\hline
\end{tabular}




\begin{tabular}{|c|c|c|c|}
\hline место & 49 & 44 & 34 \\
\hline молчать & 50 & 85 & 59 \\
\hline маленький & 51 & 48 & 65 \\
\hline жена & 52 & 84 & 139 \\
\hline новый & 53 & 61 & 66 \\
\hline чувствовать & 54 & 152 & 197 \\
\hline жить & 55 & 53 & 64 \\
\hline минута & 56 & 101 & 146 \\
\hline сторона & 57 & 78 & 35 \\
\hline молодой & 58 & 59 & 147 \\
\hline старый & 59 & 77 & 60 \\
\hline уйти & 60 & 94 & 62 \\
\hline выйти & 61 & 57 & 45 \\
\hline мысль & 62 & 102 & 130 \\
\hline стена & 63 & 126 & 80 \\
\hline сделать & 64 & 108 & 117 \\
\hline стол & 65 & 64 & 51 \\
\hline взять & 66 & 52 & 39 \\
\hline делать & 67 & 100 & 87 \\
\hline отец & 68 & 55 & 75 \\
\hline дети & 69 & 107 & 198 \\
\hline леса & 70 & 47 & 73 \\
\hline каждый & 71 & 90 & 79 \\
\hline город & 72 & 79 & 47 \\
\hline ходить & 73 & 73 & 76 \\
\hline улица & 74 & 74 & 70 \\
\hline свет & 75 & 148 & 115 \\
\hline лежать & 76 & 72 & 72 \\
\hline нужный & 77 & 68 & 49 \\
\hline вечер & 78 & 69 & 48 \\
\hline толпа & 79 & 103 & \\
\hline можно & 80 & & 95 \\
\hline последний & 81 & 86 & 83 \\
\hline тяжелый & 82 & 157 & 143 \\
\hline вода & 83 & 123 & 52 \\
\hline небо & 84 & 92 & 116 \\
\hline слышать & 85 & 116 & 129 \\
\hline стоить & 86 & 104 & 92 \\
\hline женщина & 87 & 67 & 91 \\
\hline понять & 88 & 125 & 100 \\
\hline бог & 89 & 65 & 211 \\
\hline понимать & 90 & 135 & 127 \\
\hline почтить & 91 & 142 & 156 \\
\hline сила & 92 & 128 & 90 \\
\hline лета & 93 & 106 & 145 \\
\hline ответить & 94 & 122 & 111 \\
\hline самый & 95 & 120 & 86 \\
\hline три & 96 & 98 & 68 \\
\hline мать & 97 & 113 & 102 \\
\hline год & 98 & 80 & 74 \\
\hline воздух & 99 & 164 & 137 \\
\hline утро & 100 & 81 & 55 \\
\hline хотеться & 101 & 150 & 227 \\
\hline глядеть & 102 & 82 & 123 \\
\hline губа & 103 & 115 & 82 \\
\hline
\end{tabular}




\begin{tabular}{|c|c|c|c|}
\hline тело & 104 & 133 & 84 \\
\hline больший & 105 & 99 & 63 \\
\hline смерть & 106 & 163 & 223 \\
\hline конец & 107 & 96 & 89 \\
\hline кричать & 108 & 129 & 94 \\
\hline начало & 109 & 145 & 144 \\
\hline ряд & 110 & 119 & 106 \\
\hline слушать & 111 & 93 & 118 \\
\hline длинный & 112 & 188 & 158 \\
\hline угол & 113 & 167 & 110 \\
\hline вера & 114 & & \\
\hline грудь & 115 & 124 & 103 \\
\hline солдат & 116 & 62 & \\
\hline ждать & 117 & 87 & 142 \\
\hline подумать & 118 & 170 & 122 \\
\hline далекий & 119 & 121 & 125 \\
\hline остаться & 120 & 131 & 108 \\
\hline взгляд & 121 & 153 & 213 \\
\hline милый & 122 & 176 & \\
\hline увидеть & 123 & 91 & 107 \\
\hline солнце & 124 & 97 & 78 \\
\hline остановиться & 125 & 155 & 133 \\
\hline чувство & 126 & & \\
\hline волос & 127 & 173 & 155 \\
\hline тихий & 128 & & 196 \\
\hline дать & 129 & 63 & 98 \\
\hline плечо & 130 & 109 & 96 \\
\hline смеяться & 131 & 183 & 189 \\
\hline шаг & 132 & 158 & 179 \\
\hline деньга & 133 & 178 & 249 \\
\hline любовь & 134 & 112 & \\
\hline страшный & 135 & & 241 \\
\hline прийти & 136 & 89 & 157 \\
\hline дорогой & 137 & 132 & 97 \\
\hline подойти & 138 & 130 & 128 \\
\hline холодный & 139 & & 246 \\
\hline слеза & 140 & 162 & 182 \\
\hline бояться & 141 & 95 & 149 \\
\hline девушка & 142 & 191 & 171 \\
\hline красивый & 143 & & \\
\hline целый & 144 & 154 & 200 \\
\hline господин & 145 & 146 & \\
\hline муж & 146 & 166 & 236 \\
\hline отвечать & 147 & & \\
\hline хороший & 148 & 127 & 172 \\
\hline работа & 149 & 114 & 50 \\
\hline высокий & 150 & 138 & 186 \\
\hline пройти & 151 & 199 & 176 \\
\hline веселый & 152 & & 232 \\
\hline становиться & 153 & & \\
\hline посмотреть & 154 & 177 & 160 \\
\hline странный & 155 & & \\
\hline войти & 156 & & 185 \\
\hline встать & 157 & 187 & 178 \\
\hline давать & 158 & 174 & 124 \\
\hline
\end{tabular}




\begin{tabular}{|c|c|c|c|}
\hline звук & 159 & & \\
\hline сильный & 160 & & \\
\hline $\mathrm{COH}$ & 161 & 184 & 175 \\
\hline иногда & 162 & & \\
\hline красный & 163 & 110 & 54 \\
\hline огромный & 164 & & 201 \\
\hline село & 165 & 171 & 104 \\
\hline ужас & 166 & & \\
\hline крикнуть & 167 & & 180 \\
\hline широкий & 168 & & 168 \\
\hline бежать & 169 & 134 & 85 \\
\hline вид & 170 & & 254 \\
\hline продолжать & 171 & & \\
\hline плакать & 172 & 156 & 237 \\
\hline улыбаться & 173 & & \\
\hline похожий & 174 & & \\
\hline уходить & 175 & 151 & 154 \\
\hline лошадь & 176 & 139 & 93 \\
\hline огонь & 177 & & 135 \\
\hline заметить & 178 & & 190 \\
\hline знакомый & 179 & 193 & \\
\hline иметь & 180 & & 167 \\
\hline полный & 181 & & 169 \\
\hline весело & 182 & & \\
\hline сын & 183 & 161 & 126 \\
\hline выходить & 184 & 185 & 243 \\
\hline дрожать & 185 & & 276 \\
\hline разговор & 186 & & 209 \\
\hline найти & 187 & 137 & 132 \\
\hline спрашивать & 188 & 189 & 265 \\
\hline тонкий & 189 & & 229 \\
\hline письмо & 190 & 117 & \\
\hline умереть & 191 & & 253 \\
\hline палец & 192 & 159 & 99 \\
\hline серый & 193 & 194 & 119 \\
\hline показаться & 194 & & \\
\hline снег & 195 & & 140 \\
\hline бледный & 196 & & \\
\hline поднять & 197 & & 181 \\
\hline товарищ & 198 & 105 & 38 \\
\hline черта & 199 & & 192 \\
\hline забыть & 200 & & \\
\hline мир & 201 & & 174 \\
\hline рабочий & 202 & & 112 \\
\hline синий & 203 & & 136 \\
\hline стараться & 204 & & \\
\hline двор & 205 & 180 & 153 \\
\hline начинать & 206 & & 273 \\
\hline тоска & 207 & & \\
\hline помнить & 208 & & \\
\hline дорога & 209 & 168 & 134 \\
\hline больной & 210 & & \\
\hline сталь & 211 & & 161 \\
\hline живой & 212 & 175 & 199 \\
\hline ребенок & 213 & & \\
\hline
\end{tabular}




\begin{tabular}{|c|c|c|c|}
\hline сень & 214 & 140 & \\
\hline бросить & 215 & & 141 \\
\hline ветер & 216 & 149 & 113 \\
\hline студент & 217 & & \\
\hline работать & 218 & & 109 \\
\hline улыбка & 219 & & \\
\hline батюшка & 220 & & \\
\hline близкий & 221 & & \\
\hline радость & 222 & 196 & 191 \\
\hline движение & 223 & & \\
\hline народ & 224 & 198 & 164 \\
\hline дерево & 225 & & 225 \\
\hline хозяин & 226 & & 274 \\
\hline играть & 227 & & 207 \\
\hline счастье & 228 & & \\
\hline ехать & 229 & & 159 \\
\hline почувствовать & 230 & & \\
\hline чужой & 231 & & 272 \\
\hline оставаться & 232 & & \\
\hline оставить & 233 & & \\
\hline поднять & 234 & 141 & \\
\hline придти & 235 & & \\
\hline светлый & 236 & & \\
\hline гореть & 237 & & \\
\hline десять & 238 & & \\
\hline доктор & 239 & & 233 \\
\hline река & 240 & & 224 \\
\hline пьяный & 241 & & \\
\hline яркий & 242 & & \\
\hline вернуться & 243 & & 187 \\
\hline рубль & 244 & & \\
\hline крик & 245 & & \\
\hline легкий & 246 & 195 & 226 \\
\hline сестра & 247 & & \\
\hline тень & 248 & & \\
\hline тишина & 249 & & 231 \\
\hline деревня & 250 & 192 & 150 \\
\hline
\end{tabular}

